\title{
Pulmonary prostacyclin synthase overexpression in transgenic mice protects against development of hypoxic pulmonary hypertension
}

\author{
Mark W. Geraci, ${ }^{1}$ Bifeng Gao, ${ }^{1}$ David C. Shepherd, ${ }^{1}$ Mark D. Moore, ${ }^{1}$ Jay Y. Westcott, ${ }^{2}$ \\ Karen A. Fagan, ${ }^{1,2}$ Lori A. Alger, ${ }^{1}$ Rubin M. Tuder, ${ }^{1,2,3}$ and Norbert F. Voelkel ${ }^{1,2}$ \\ ${ }^{1}$ Department of Medicine, Division of Pulmonary Sciences and Critical Care Medicine, \\ ${ }^{2}$ Pulmonary Hypertension Center, and \\ ${ }^{3}$ Department of Pathology, University of Colorado Health Sciences Center, Denver, Colorado 80262, USA \\ Address correspondence to: Mark W. Geraci, Division of Pulmonary Sciences and Critical Care Medicine, University of Colorado \\ Health Sciences Center, Campus Box C-272, 4200 E. Ninth Avenue, Denver, Colorado 80262, USA. Phone: (303) 315-7047; \\ Fax: (303) 315-5632; E-mail: mark.geraci@uchsc.edu. \\ Received for publication November 30, 1998, and accepted in revised form May 5, 1999.
}

\begin{abstract}
Prostacyclin synthase (PGIS) is the final committed enzyme in the metabolic pathway leading to prostacyclin $\left(\mathrm{PGI}_{2}\right)$ production. Patients with severe pulmonary hypertension have a PGIS deficiency of their precapillary vessels, but the importance of this deficiency for lung vascular remodeling remains unclear. We hypothesized that selective pulmonary overexpression of PGIS may prevent the development of pulmonary hypertension. To study this hypothesis, transgenic mice were created with selective pulmonary PGIS overexpression using a construct of the $3.7-\mathrm{kb}$ human surfactant protein-C (SP-C) promoter and the rat PGIS cDNA. Transgenic mice $\left(\mathrm{Tg}^{+}\right)$and nontransgenic littermates $\left(\mathrm{Tg}^{-}\right)$were subjected to a simulated altitude of $17,000 \mathrm{ft}$ for 5 weeks, and right ventricular systolic pressure (RVSP) was measured. Histology was performed on the lungs. $\mathrm{The}^{\mathrm{Tg}^{+}}$mice produced 2 -fold more pulmonary 6 -keto prostaglandin $\mathrm{F}_{1 \alpha}\left(\mathrm{PGF}_{1 \alpha}\right)$ levels than did $\mathrm{Tg}^{-}$mice. After exposure to chronic hypobaric hypoxia, $\mathrm{Tg}^{+}$ mice have lower RVSP than do $\mathrm{Tg}^{-}$mice. Histologic examination of the lungs revealed nearly normal arteriolar vessels in the $\mathrm{Tg}^{+}$mice in comparison with vessel wall hypertrophy in the $\mathrm{Tg}^{-}$mice. These studies demonstrate that $\mathrm{Tg}^{+}$mice were protected from the development of pulmonary hypertension after exposure to chronic hypobaric hypoxia. We conclude that PGIS plays a major role in modifying the pulmonary vascular response to chronic hypoxia. This has important implications for the pathogenesis and treatment of severe pulmonary hypertension.
\end{abstract}

J. Clin. Invest. 103:1509-1515 (1999).

\section{Introduction}

Prostacyclin $\left(\mathrm{PGI}_{2}\right)$ is a lipid mediator derived from arachidonic acid (AA). Prostacyclin is the main product of AA in all vascular tissues tested to date (1). Once released from cells, prostacyclin acts as an autocrine and paracrine effector to regulate the function of various differentiated cells and platelets through specific receptors, G-protein activation, and stimulation of adenyl cyclase (2). Prostacyclin has several important biologic effects. It is the most potent endogenous inhibitor of platelet aggregation yet discovered (1), and, as a product of the vascular wall endothelium and smooth muscle cells, $\mathrm{PGI}_{2}$ produces vasodilation of all vascular beds studied (3). $\mathrm{PGI}_{2}$ inhibits both proliferation and DNA synthesis of smooth muscle cells $(4,5)$. Along with other prostaglandins, $\mathrm{PGI}_{2}$ shares a cytoprotective activity that is not yet completely understood. For example, in models of myocardial infarction, prostacyclin reduces infarct size and oxygen demand $(6,7)$.

Prostacyclin synthase (PGIS), a membrane-associated P450-like enzyme with a molecular mass of $52 \mathrm{kDa}$, catalyzes the rearrangement of prostaglandin $\mathrm{H}_{2}\left(\mathrm{PGH}_{2}\right)$ to $\mathrm{PGI}_{2}$. Within the lungs, PGIS is located in the endothelium and smooth muscle cells of arteries, as well as throughout the epithelial lining cells (8). Recently, the bovine $(9,10)$ and the human $(11)$ cDNAs have been cloned. Transfection of the PGIS cDNA into rat vascular smooth muscle cells resulted in increased $\mathrm{PGI}_{2}$ synthesis and inhibition of cell growth, suggesting that in vivo gene transfer of PGIS may be useful for gene therapy for vascular diseases (12).

Decreased prostacyclin production has been implicated in the pathogenesis of severe pulmonary hypertension, including primary pulmonary hypertension (PPH) - an often fatal disease, with a predilection for young women, in which the pulmonary vasculature undergoes extensive remodeling, leading to elevations in pulmonary artery pressure and pulmonary vascular resistance (13). Christman et al. (14) have shown that patients with PPH have an abnormally elevated ratio of urinary thromboxane to prostacyclin metabolites, and they propose that this imbalance could lead to pulmonary vasoconstriction and local thrombosis. Badesch et al. (15) reported that chronic hypobaric hypoxia induces the development of severe pulmonary hypertension in neonatal calves, accompanied by greatly diminished basal and stimulated $\mathrm{PGI}_{2}$ synthesis in the remodeled arteries and isolated endothelial cells derived from hypertensive arteries. Using a rat model, Rabinovitch et al. (16) have shown that induction of prostacyclin release prevents hypoxic pulmonary hypertension and vascular changes. Recently, Tuder et al. 


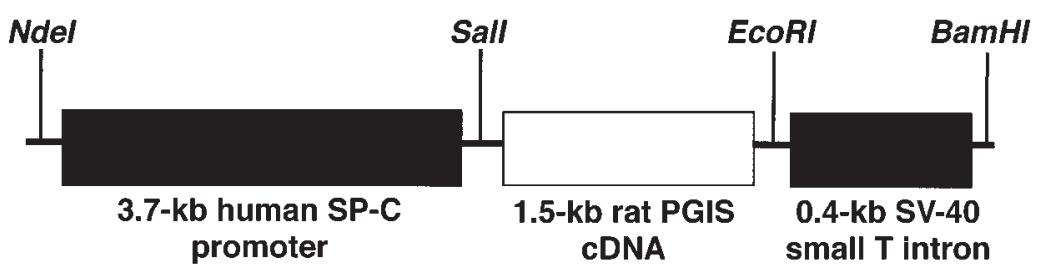

Figure 1

Human SP-C/rat PGIS transgene construct. Pertinent restriction sites used in cloning are noted. SV-40 small T intron is used as a gene-specific probe for Northern blots, Southern blots, and in situ hybridization studies.

(17) examined the lungs of patients with PPH and secondary pulmonary hypertension and found a decreased expression of the PGIS gene in the vessels, indicating that the lung vascular prostacyclin synthesis is impaired in severe pulmonary hypertension.

Prostaglandin replacement has proved beneficial in several clinical settings. In patients with severe PPH, continuous intravenous prostacyclin has been recognized as a therapeutic breakthrough, resulting in sustained clinical and hemodynamic improvement and improved survival $(18,19)$. Aerosolized $\mathrm{PGI}_{2}$ reduces pulmonary hypertension and shunt and improves arterial oxygenation in the absence of systemic effects in patients with severe pneumonia (20); this form of therapy is as effective as inhaled nitric oxide in patients with acute respiratory distress syndrome (21). In an animal model of respiratory failure with pulmonary hypertension, inhaled prostacyclin (acting transepithelially with pulmonary selectivity) was superior to intravenous prostacyclin in improving oxygenation and pulmonary hemodynamics (22).

The goal of the present study was to examine the role of pulmonary overproduction of prostacyclin on the development of pulmonary hypertension by using a transgenic mouse that was developed to selectively overexpress PGIS in the lung epithelial lining cells. To determine the biologic effects of PGIS overexpression, animals were exposed to chronic hypoxia, and assessment of right ventricular pressures and pulmonary vascular remodeling was performed. We demonstrate that overexpression of PGIS prevents the pulmonary vascular remodeling that occurs because of chronic hypoxia.

\section{Methods}

Construction of the SP-C/PGIS transgene. Using a combination of PCR and standard hybridization library screening, we determined the entire coding sequence for the rat PGIS cDNA. This nucleotide sequence has been submitted to GenBank/EMBL with accession no. U53855. The coding region of the rat PGIS cDNA shows $82 \%$ homology to the bovine sequence $(9,10)$ and $82.5 \%$ homology to the human (11) cDNA. A full-length cDNA for the rat PGIS was amplified by PCR from a rat lung 5 -stretch cDNA library constructed in a $\lambda$ gt 11 vector (CLONTECH Laboratories Inc., Palo Alto, California, USA) using a high-fidelity $p f u$ DNA polymerase (Stratagene, La Jolla, California, USA) with PCR primers that encompass the start (5'-CTG GAA TTC CGG GAG CCA TG-3') and stop (5'-AGT GTC TGC TCC ACA GGT CA-3') codons of the PGIS cDNA. A complete open reading frame was demonstrated by sequence analysis. The University of Colorado Cancer Center DNA Sequencing Core performed automated sequencing, using Applied Biosystems 377 and 373 sequencers. (Perkins-Elmer, Foster City, California,
USA). The 3.7 hSP-C/SV-40 plasmid was a generous gift from Jeffrey A. Whitsett (Children's Hospital Medical Center, Cincinnati, Ohio, USA). This pUC 18 plasmid contains the 3.7$\mathrm{kb}$ flanking sequence of the human SP-C promoter in addition to the SV-40 small T intron as a polyadenylation signal $(23,24)$. This construct has been proved to express transgenes in the distal lung epithelium and alveoli exclusively (24). The rat PGIS cDNA was cloned into the SalI/EcoRI site of the plasmid, creating the SP-C promoter-PGIS cDNA fusion gene (Figure 1). The proper cloning orientation of our construct was confirmed by direct sequence analysis.

Generation and identification of transgenic mice. DNA comprising the transgene was prepared for pronuclear injections as described (25). Jon Neumann (University of Cincinnati Transgenic Mouse Core Facility, Cincinnati, Ohio, USA) performed pronuclear injections. A total of 600 pronuclear injections in $\mathrm{FVB} / \mathrm{N}$ mice were performed, resulting in the generation of 40 pups. Identification of transgenic offspring (founder mice) was done by analysis of genomic DNA isolated from tail biopsies with the QIAamp Tissue Kit according to the manufacturer's protocols (QIAGEN Inc., Santa Clarita, California, USA). PCR analysis of the genomic DNA was performed using, as control, primers from the TSH- $\beta$ gene to ensure the quality of genomic DNA (sense primer: 5'-TCC TCA AAG ATG CTC ATT AG-3'; antisense primer: $5^{\prime}$-GTA ACT CAC TCA TGC AAA GT-3'). Primers spanning the 400 -bp segment of the SV-40 small T intron were designed to detect the presence of the transgene (sense primer: 5'-TGT GAA GGA ACC TTA CTT CTG TGG-3'; antisense primer: 5'-TGG ACA AAC CAC AAC TAG AAT GCAC- $\left.3^{\prime}\right)$. Screening of the 40 pups from the 600 pronuclear injections demonstrated the identification of 7 pups as founders. To maintain an isogenic strain, all mice were propagated as heterozygous transgenic mice by breeding with wild-type FVB/N mice. FVB/N mice were chosen because of the enlarged male pronucleus in this strain and the resultant relative ease of microinjection. F2-generation mice were used in all the studies.

Southern blot analysis. To confirm the PCR results and identify transgenic mice bearing the PGIS transgene, genomic DNA was isolated as just described, digested with EcoRI, separated on a $0.9 \%$ agarose gel, and transferred to Nytran membrane (Schleicher \& Schuell Inc., Keene, New Hampshire, USA). Blots were air dried and baked. Hybridization was performed using a ${ }^{32} \mathrm{P}-$ labeled probe of the 400-bp product of the SV-40 small T intron generated from the primers already described here, using ExpressHyb (CLONTECH Laboratories Inc.) according to the manufacturer's specifications. The blot was exposed to Kodak XAR film at $-80^{\circ} \mathrm{C}$.

Northern blot analysis. Animals were sacrificed by lethal injection of $50 \mathrm{mg}$ sodium pentobarbital (Abbott Laboratories, North Chicago, Illinois, USA). Lungs were immediately frozen in an ethanol/dry ice bath and stored at $-70^{\circ} \mathrm{C}$. Total RNA was extracted using Tri-Reagent (Molecular Research Center, Cincinnati, Ohio, USA) according to the manufacturer's protocol. The concentration of each sample was determined based on the 


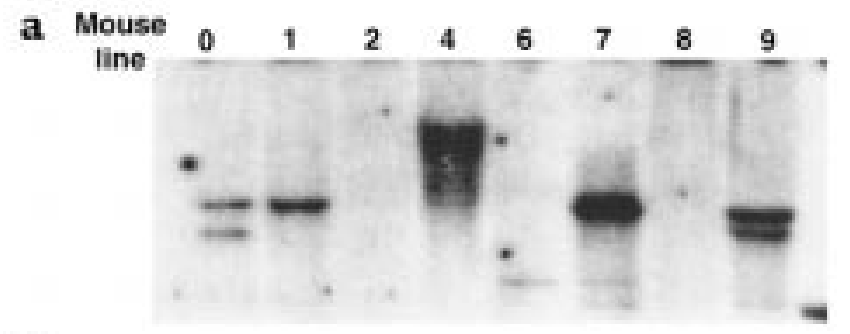

b

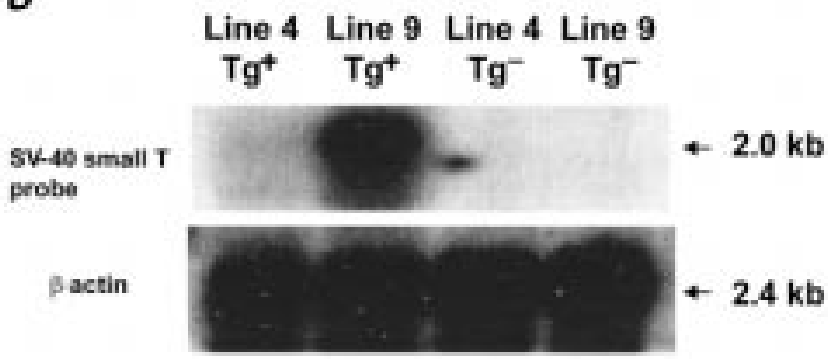

Figure 2

Southern (a) and Northern (b) blot analysis of transgenic mice and nontransgenic littermates. Representative autoradiograms are shown. (a) For Southern analysis, each lane was loaded with equal amounts of genomic DNA digested with EcoRI and probed with the 0.4-kb SV-40 small T intron as described in Methods. Because the CDNA for PGIS has an internal EcoRI site, the position of the transgene signal cannot be predicted. Lines 2 and 8 represent nontransgenic animals, and no signal is detected. (b) Total RNA was prepared from the F2 offspring of the founders in lines 4 and 9. Twenty micrograms of RNA was loaded in each lane, and the blot was probed with both SV-40 small T intron as a gene-specific probe and $\beta$ actin to demonstrate equal loading. Line 4 represents a low-expressing line, and line 9 represents a high-expressing line. There is no transgene expression in the nontransgenic littermates for each of these lines.

absorbance at $260 \mathrm{~nm}\left(\mathrm{~A}_{260}\right)$. The purity of each sample was determined based on the ratio of $A_{260}$ to $A_{280}\left(A_{260: 280}\right)$. A range of 1.6-2.0 was considered adequately pure. Total RNA (20 $\mu \mathrm{g} /$ lane) was separated according to size on a $1 \%$ agarose $/ 0.6 \mathrm{M}$ formaldehyde gel and transferred to a synthetic membrane (Maximum Strength Nytran Plus; Schleicher \& Schuell Inc.) using a standard capillary blot technique. Hybridization, washing, and autoradiography were performed as described for Southern analysis. Subsequently, all membranes were stripped and probed with $\beta$-actin as controls to ensure equal loading and transfer. Autoradiographs were analyzed using SigmaGel gel analysis software (Jandel Scientific, San Rafael, California, USA).

In situ bybridization. Fresh lung tissue was inflated with lowmelt agarose and snap-frozen as described previously (26). Frozen sections of lung tissue were then submitted to detection of SV-40 T antigen by in situ hybridization (27). The SV-40 small $\mathrm{T}$ intron was PCR amplified as described previously and cloned into the pGEM T vector (Promega Corp., Madison, Wisconsin, USA). Digoxigenin-labeled antisense and sense cRNA probes were synthesized from the T7 and SP6 polymerase promoters, respectively (Genius IV kit; Boehringer Mannheim Biochemicals, Indianapolis, Indiana, USA). The antisense and sense probes were applied in parallel sections within the same slides at $2 \mathrm{ng} / \mathrm{mL}$ and then hybridized at $37^{\circ} \mathrm{C}$ overnight. The detection of the hybridization product was allowed to proceed for approximately 4 hours. Two lung slides per animal were examined by in situ hybridization.

6-keto PGF $F_{1 \alpha}$ assay for PGIS activity. Lungs from both $\mathrm{Tg}^{+}$and $\mathrm{Tg}^{-}$animals were weighed and were homogenized in a buffer containing Earle's Balanced Salt Solution (Sigma Chemical Co., St. Louis, Missouri, USA) and $0.1 \%$ BSA. AA $(3 \mu \mathrm{g} / \mathrm{mL})$ was added to the sample, which was then diluted 1:3 with methanol. Using methods described previously (28), we have examined the lung homogenates to determine the 6-keto PGF $_{1 \alpha}$ levels within the lungs. The assay was performed in a blinded fashion (by J.Y. Westcott) using coded sample tubes.

Acute hypoxia exposure. For exposure to acute hypoxia, male mice 10-12 weeks old were placed in an acrylic chamber (FIO2 $=0.1$ ) for 15 minutes. During hemodynamic assessment, the animals were maintained in the hypoxic environment (except for the brief period to administer anesthesia) by placing them in a cylinder with flow-by oxygen at FIO2 $=0.1$. For these studies, $14 \mathrm{Tg}-$ and $10 \mathrm{Tg}+$ animals were examined.

Hypobaric hypoxia exposure. For exposure to hypobaric hypoxia, male mice 12 weeks old were housed in a hypobaric chamber for 5 weeks at a simulated altitude of $17,000 \mathrm{ft}(\mathrm{Pb}=410$ $\mathrm{mmHg}$; inspired $\mathrm{PO}_{2}=76 \mathrm{mmHg}$ ). Five $\mathrm{Tg}^{+}$animals and $5 \mathrm{Tg}^{-}$ littermates were used for these studies. Exposure was continuous, with less than 1 hour per day interruption for animal care.

Hemodynamic assessment. Direct right ventricular systolic pressure (RVSP) was measured as described previously (29). Briefly, animals were anesthetized with ketamine and xylazine (100 $\mathrm{mg} / \mathrm{kg}$ and $15 \mathrm{mg} / \mathrm{kg}$, respectively) by way of a hindquarter intramuscular injection. After adequate sedation, the animals were placed in a supine position, breathing room air. The pressure transducer was calibrated to a zero point at the mid-anteroposterior diameter of the chest. A 26-gauge needle was introduced percutaneously into the thorax through a subxiphoid approach. Right and left ventricular pressures were measured using a pressure transducer (Gulton-Statham, Costa Mesa, California, USA) and recorded on a multichannel recorder (Grass Instruments, Quincy, Massachusetts, USA). Approximately 10 recordings per animal were made. After hemodynamic measurement, animals were sacrificed and tissues were fixed for morphometric analysis.

Hematocrit analysis. After animals were sacrificed, $0.2 \mathrm{~mL}$ of blood was collected by way of ventricular puncture and heparinized. Spun hematocrit was measured using capillary tubes and standard techniques. Tests were performed in duplicate for each animal, and the average was used.

Histology and morphometrics. Lung tissue, processed as already described here, was formalin fixed and paraffin embedded. A representative hematoxylin and eosin-stained section through the hilum was then coded and blindly evaluated (by R.M. Tuder) for remodeling of pulmonary arteries in the range of $30-50 \mu \mathrm{m}$ located at the level of respiratory bronchioles and origin of alveolar ducts. For the conditions of control (Denver altitude) and chronic hypoxia, each experimental animal was examined $(n=5$ for both $\mathrm{Tg}^{+}$and $\mathrm{Tg}^{-}$for each condition). An average of 16 measurements were made on each animal (range, 12-18). The measurements of the external and luminal diameter were obtained with an Interactive Digital Analyzer System (Carl Zeiss Inc., Thornwood, New York, USA) as described previously (30). The wall thickness of each artery was expressed a percentage of the vessel diameter by the formula (Ed-Id)/Ed, where Ed represents external diameter and Id represents internal diameter. Measurements were only performed on vessels that were cut transversely. Arteries cut obliquely, and pulmonary veins, were excluded from the analysis.

Statistical analysis. All values were expressed as mean \pm SEM. The data were normally distributed, and we performed unpaired $t$ tests using GraphPad Prism 2.01 for Windows 95 (GraphPad Software for Science Inc., San Diego, California, USA).

\section{Results}

Generation of transgenic mice. From 600 eggs injected with the SP-C/PGIS DNA constructs, 7 transgenic founders were generated as confirmed by Southern blot analysis of genomic DNA (Figure 2a). One male founder (line 0) had 
a

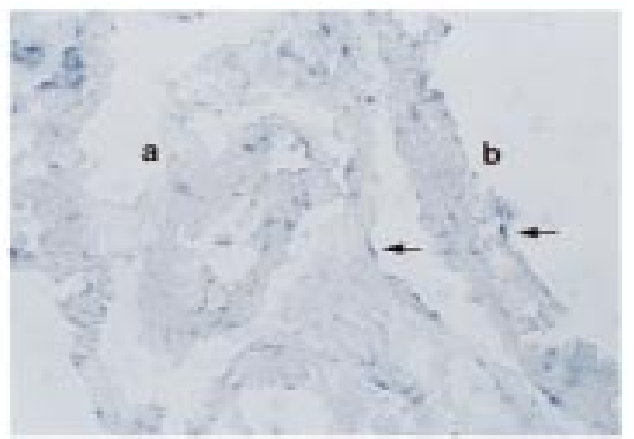

b

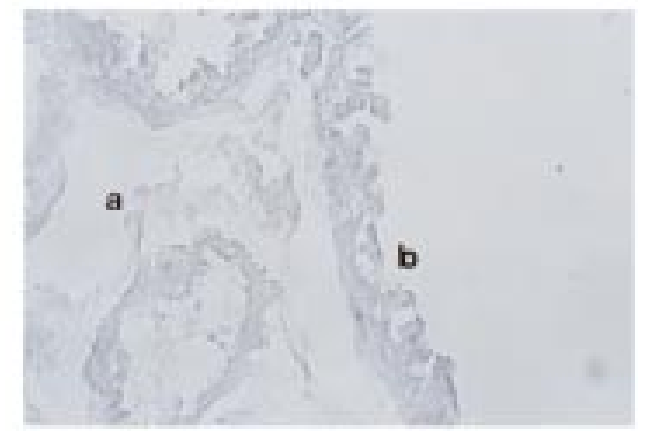

Figure 3

Detection of transgene expression by in situ hybridization. Sections from a transgenic mouse lung were hybridized to a digoxigenin-labeled genespecific probe (SV-40 small T intron). (a) Antisense probe, showing transgene expression in the distal lung epithelium. b, bronchial lumen; $a$, alveolar spaces. Arrows indicate cells with positive signal. (b) Control sense probe. Minimal staining is shown.

a large inguinal hernia and was unable to breed. One female founder (line 5) died shortly after her first parturition, as did all of her pups; this line was unable to be propagated or further studied. The remaining 5 founders have been bred with wild-type FVB/N mice and were found to pass the transgene, following Mendelian rules. To test for expression of the transgene, Northern analysis of total lung RNA was performed using the SV-40 small $\mathrm{T}$ intron as a gene-specific probe on all lines. Line 9 proved to be a high-expressing line, whereas line 4 was a low-expressing line (Figure 2b). Line 7 represents a line with intermediate expression. Line 9 was chosen for further study based on the consistent high-level expression of PGIS mRNA by Northern analysis, and is the line used in all of the following studies. Except when noted, all data refer to animals from line 9.

The transgene is expressed in distal respiratory epithelium. Previously, the SP-C promoter has been shown to direct pulmonary-specific gene expression in transgenic mice (24). Although generally directing expression in alveolar type II cells, this promoter variably directs expression in other distal epithelial cells, such as type I cells and bronchial cells. To determine the pattern of transgene expression in our highest-expressing line, in situ hybridization was performed using the SV-40 small $\mathrm{T}$ intron as a gene-specific probe. Figure 3 demonstrates that the transgene is expressed predominantly in alveolar lining cells but also in bronchial epithelial cells.

PGIS enzyme activity is increased in transgenic animals. To determine whether elevated levels of functional PGIS activity occurred in transgenic animals, a PGIS enzyme activity assay was performed. The lung tissue levels of the stable $\mathrm{PGI}_{2}$ metabolite 6-keto $\mathrm{PGF}_{1 \alpha}$ were measured on coded samples after incubation of the lung tissue with AA. We found that $\mathrm{Tg}^{+}$animals in line 9 produced nearly twice as much 6-keto $\mathrm{PGF}_{1 \alpha}$ in their lung tissue as did $\mathrm{Tg}^{-}$littermates $(3,107 \pm 608 \mathrm{ng} / \mathrm{g}$ tissue $[n=10]$ vs. 1,559 $\pm 277 \mathrm{ng} / \mathrm{g}$ tissue $[n=11] ; P=0.01$ ) (Figure 4). In an intermediate-expressing line (line 7 ), $\mathrm{Tg}^{+}$animals produced $47 \%$ more 6-keto $\mathrm{PGF}_{1 \alpha}$ than did $\mathrm{Tg}^{-}(2,104 \pm$ $195.7 \mathrm{ng} / \mathrm{g}$ tissue $[n=16]$ vs. $1,431 \pm 182 \mathrm{ng} / \mathrm{g}$ tissue $[\mathrm{n}=$ 20]; $P<0.05)$ (data not shown).

Both PGIS transgenic animals and their nontransgenic littermates demonstrate a polycythemic response with exposure to chronic hypoxia. At Denver's altitude $(\mathrm{Pb}=630 \mathrm{mmHg}$, inspired $\left.\mathrm{PO}_{2}=122 \mathrm{mmHg}\right), \mathrm{Tg}^{+}(n=5)$ and $\mathrm{Tg}^{-}$animals $(n=5)$ had similar hematocrit values $(32.2 \pm 1.7 \%$ vs. 33.2 $\pm 2.8 \% ; \mathrm{P}=0.77$, not significant [ns]). In response to chronic hypoxia, both $\mathrm{Tg}^{+}(n=5)$ and $\mathrm{Tg}^{-}(n=5)$ animals developed polycythemia ( $\mathrm{Tg}^{+}: 32.2 \pm 1.7 \%$ vs. $47.8 \pm 2.8 \%$, $P=0.002 ; \mathrm{Tg}: 33.2 \pm 2.8 \%$ vs. $46.4 \pm 0.8 \%, P=0.005)$. The extent of polycythemia was the same for $\mathrm{Tg}^{+}$and $\mathrm{Tg}^{-}$animals ( $47.8 \pm 2.8 \%$ vs. $46.4 \pm 0.8 \% ; P=0.78$, ns) (Figure 5 ).

PGIS-expressing mice do not exbibit a pulmonary bypertensive response to acute hypoxia. To ascertain whether PGISexpressing mice had a blunted response to hypoxic vasoconstriction, $\mathrm{Tg}^{+}$mice $(n=10)$ and $\mathrm{Tg}^{-}$littermates $(n=14)$ were exposed to acute hypoxia $\left(\mathrm{FIO}_{2}=0.1\right)$ for 15 minutes, and assessment of RVSP was performed. At baseline (Denver's altitude of 5,280 ft), $\operatorname{Tg}^{+}(n=5)$ and $\operatorname{Tg}^{-}(n=5)$ displayed no difference in RVSP (30.0 \pm 1.2 $\mathrm{mmHg}$ vs. $31.1 \pm 2.4 \mathrm{mmHg} ; P=0.68$, ns). After acute hypoxia, $\mathrm{Tg}^{+}$mice did not show vasoconstriction, whereas $\mathrm{Tg}^{-}$mice demonstrated elevated RVSP (30.1 \pm $1.4 \mathrm{mmHg}$ vs. $35.4 \pm 1.4 \mathrm{mmHg} ;=0.02$ ) (Figure 6).

PGIS-overexpressing mice are protected from the development of chronic bypoxic pulmonary bypertension. To determine the biologic efficacy of overexpression of PGIS, $\mathrm{Tg}^{+}$mice and $\mathrm{Tg}^{-}$ littermates were exposed to a simulated altitude of 17,000 $\mathrm{ft}$ for 5 weeks. After exposure, the animals were analyzed for hematocrit, RVSP, and histologic examination of the

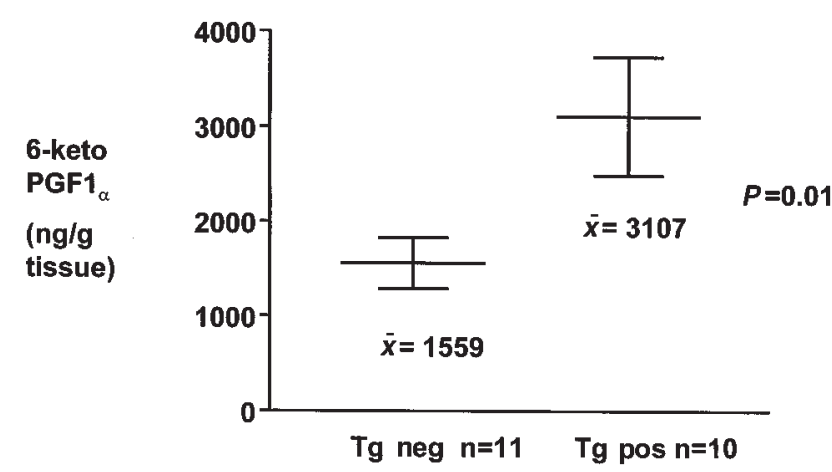

\section{Figure 4}

Pulmonary PGIS activity. Whole lungs were homogenized in a buffer containing AA. The stable breakdown product of $\mathrm{PGI}_{2}, 6$-keto $\mathrm{PGF}_{1 \alpha}$, was assayed as a direct measure of PGIS enzyme activity. Transgenic animals $(n=5)$ had significantly higher 6-keto $\mathrm{PGF}_{1 \alpha}$ production than did their nontransgenic $(n=5)$ littermates $(3,107$ vs. $1,159 \mathrm{ng} / \mathrm{g}$ tissue; $P=0.01)$. 


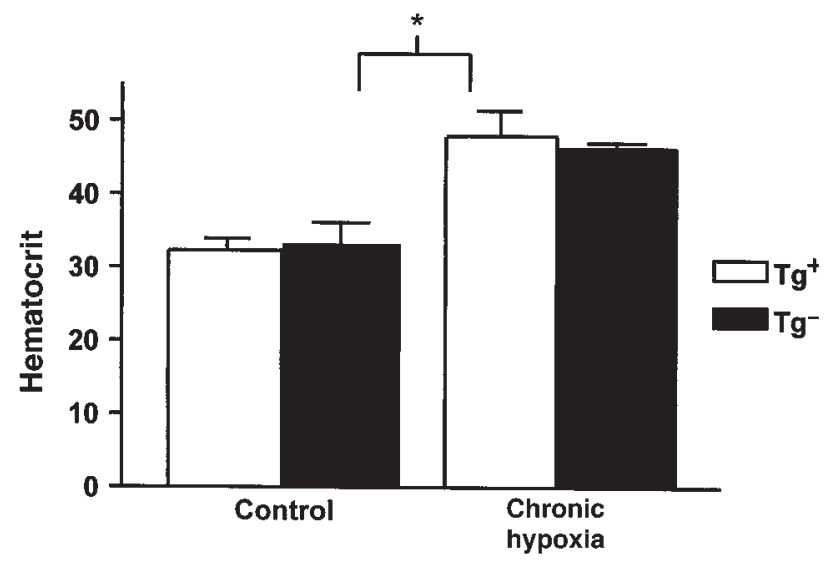

Figure 5

Hematocrits of animals at baseline and after hypobaric hypoxia exposure. Transgenic animals $(n=5)$ and nontransgenic littermates $(n=5)$ did not differ in hematocrits at baseline (32.2\% vs. $33.2 \% ; P=n s)$. After prolonged exposure to hypobaric hypoxia, both transgenic $(n=5)$ and nontransgenic $(n=5)$ animals developed significantly elevated hematocrits when compared with room air controls (32.0 vs. 47.8 for $\mathrm{Tg}^{+}\left[{ }^{*} P=\right.$ $0.002] ; 33.2$ vs. 46.4 for $\mathrm{Tg}^{-}\left[{ }^{*} P=0.005\right]$ ). The hematocrit difference between transgenic and nontransgenic littermates was not significant at altitude (47.8 vs. $46.4 ; P=\mathrm{ns})$.

lungs. RVSP was measured as an approximation of pulmonary artery pressure. $\mathrm{Tg}^{-}$animals $(n=5)$ developed significant pulmonary hypertension, with RVSP averaging $46.6 \pm 0.66 \mathrm{mmHg}$. PGIS transgenic animals $(n=5)$ did not develop pulmonary hypertension, having an average RVSP of 29.2 $\pm 4.4 \mathrm{mmHg}(P=0.001)$ (Figure 6). Transgenic animals from an intermediate-expressing line (line 7) were not protected from the development of pulmonary hypertension after chronic hypoxia. In this line, $\mathrm{Tg}^{+}$animals $(n=4)$ developed elevated RVSP to a similar extent as did the Tg littermates $(n=3)(35.3 \pm 4.9 \mathrm{mmHg}$ vs. $40.5 \pm 2.8 \mathrm{mmHg}$; $P=0.44$, ns). A power analysis (assuming a two-sided type I error of $5 \%$ ) of the data comparing $\mathrm{Tg}^{+}$and $\mathrm{Tg}^{-}$in line 7 indicates that a statistically significant difference between these groups cannot be expected unless 40 animals per group are studied, if indeed such a difference occurs.

PGIS-expressing mice have no vascular remodeling after bypobaric bypoxia. Morphometric analysis of the vasculature (small to medium-sized arteries of $30-50 \mu \mathrm{m}$ ) from control (Denver altitude) and high altitude-exposed animals was performed. A blinded observer (R.M. Tuder) quantitatively determined vessel wall thickness. At baseline in Denver, $\operatorname{Tg}^{+}(n=5)$ and $\operatorname{Tg}^{-}(n=5)$ animals showed no morphologic difference in vessel wall thickness $(0.165 \pm$ 0.009 vs. $0.167 \pm 0.007 ; P=0.85$, ns). After exposure to hypobaric hypoxia, $\mathrm{Tg}^{+}$animals $(n=5)$ developed no vessel wall hypertrophy compared with their $\mathrm{Tg}^{-}$littermates $(n=5)(0.169 \pm 0.007$ vs. $0.204 \pm 0.008 ; P=0.0015)($ Figure $7 \mathrm{a})$. As illustrated in Figure $7 \mathrm{~b}$, significant vessel wall hypertrophy developed in a $\mathrm{Tg}^{-}$animal in comparison to a $\mathrm{Tg}^{+}$littermate after exposure to hypobaric hypoxia. Of note, no animals developed inflammation in response to chronic hypoxia exposure.

\section{Discussion}

Pulmonary-specific overexpression of rat PGIS in the respiratory epithelium of transgenic mice was accomplished by a transgene directed by the promoter-enhanced elements from the $5^{\prime}$ region of the human SP-C gene. To our knowledge, our results are the first to demonstrate that the lung-specific overexpression of this gene protects against pulmonary hypertension induced by hypobaric hypoxia. These results support the hypothesis that deficient pulmonary prostacyclin synthesis $(15,17)$ may play a role in the development of pulmonary hypertension.

Although continuous $\mathrm{PGI}_{2}$ infusion has been accepted as an effective treatment of $\mathrm{PPH}$, a preclinical trial of chronic $\mathrm{PGI}_{2}$ treatment has never been performed, largely owing to the cumbersome and expensive nature of the chronic drug-delivery devices needed for this type of animal study. $\mathrm{PGI}_{2}$ and its analogues have a short biologic half-life, limiting their utility in chronic studies. $\mathrm{PGI}_{2}$ has been delivered by way of aerosolization and thus can act transepithelially. Indeed, a piglet model of respiratory failure with pulmonary hypertension revealed that inhaled $\mathrm{PGI}_{2}$ was superior to intravenous $\mathrm{PGI}_{2}$ in improving oxygenation and pulmonary hemodynamics (22). For our experiments, we chose to use the epithelial cell SP-C promoter instead of a vascular-specific promoter because we desired robust pulmonary transgene expression. We were encouraged by the previous results of effective inhalational $\mathrm{PGI}_{2}$ therapy $(20-22)$ that provide the rationale that transepithelial delivery of $\mathrm{PGI}_{2}$ to vascular structures could be achieved from epithelial cells overexpressing PGIS and providing $\mathrm{PGI}_{2}$ in a paracrine fashion.

We developed several lines of PGIS transgenic animals

\section{Figure 6}

RVSP at baseline, with acute hypoxia, and after exposure to hypobaric hypoxia. Direct right ventricular pressure was determined by a transthoracic cannulation technique as described in Methods. At baseline (Control, Denver altitude), transgenic $(n=5)$ and nontransgenic $(n=5)$ animals show similar RVSP (30.0 vs. $31.1 \mathrm{mmHg} ; P=0.68$, ns). With acute hypoxia, transgenic mice $(n=10)$ did not show vasoconstriction, compared with their nontransgenic littermates $(n=14)\left(30.1\right.$ vs. $\left.35.4 \mathrm{mmHg} ;{ }^{*} P=0.02\right)$. After 5 weeks of exposure to hypobaric hypoxia, nontransgenic animals $(n=$ 5 ) had significantly higher RVSP than did PGIS transgenic animals $(n=5)\left(46.6\right.$ vs. $\left.29.2 \mathrm{mmHg} ;{ }^{*} P=0.001\right)$.

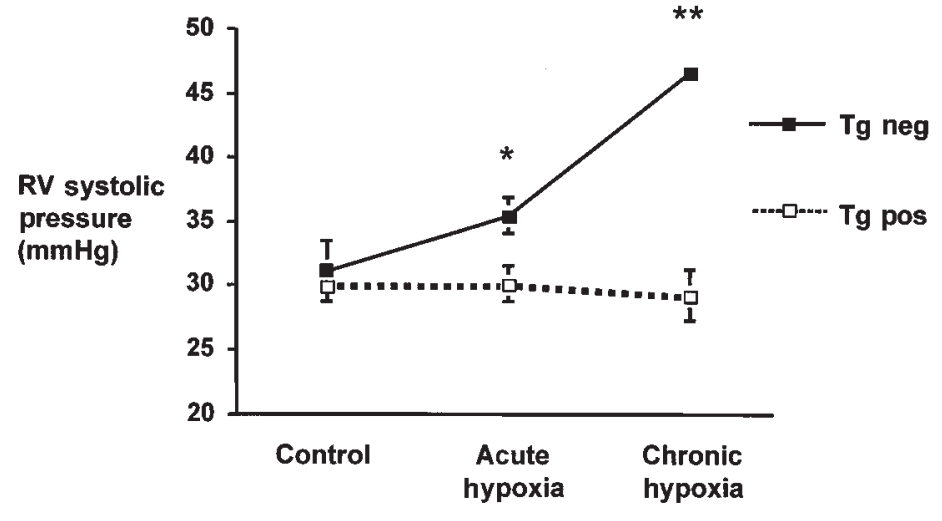


a

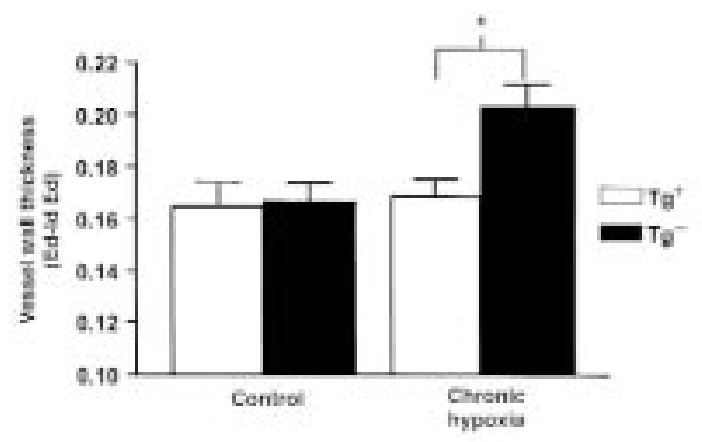

b

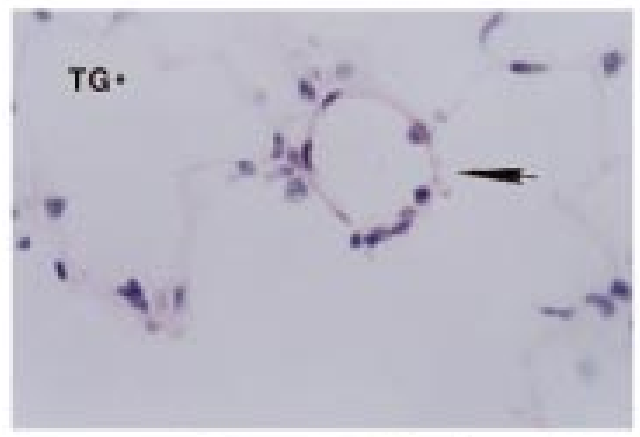

c

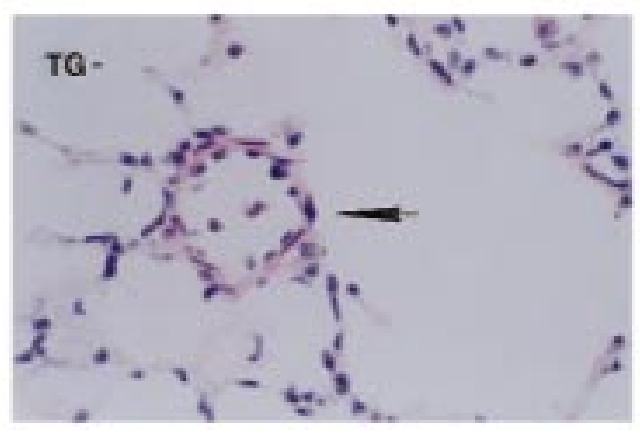

Figure 7

Histology of lungs from high altitude-exposed animals. (a) Comparison of the vessel wall thickness of small- to medium-sized (30-50 $\mu \mathrm{m})$ pulmonary arteries. Vessel wall thickness was calculated by external diameter (Ed) minus internal diameter (Id) divided by the external diameter: (Ed-Id)/Ed. At baseline (Control, Denver altitude), transgenic $(n=5)$ and nontransgenic $(n=5)$ animals have similar vessel wall thickness ( 0.165 vs. $0.167 ; P=0.85, \mathrm{~ns})$. After chronic hypoxia, nontransgenic animals $(n=$ $5)$ had significantly more vessel wall hypertrophy of small- to mediumsized vessels than did transgenic mice $(n=5)\left(0.21\right.$ vs. 0.16 ; $\left.{ }^{*} P=0.0015\right)$. (b) Vascular histology $(\times 400)$. Vessels of comparable diameters, showing the hypertrophy of the vessel wall in nontransgenic animals compared with transgenic animals. $\mathrm{Tg}^{-}$, nontransgenic littermate; $\mathrm{Tg}^{+}$, transgenic animal. Arrows indicate the measured vessels. Along with vessel wall hypertrophy, the $\mathrm{Tg}^{-}$vessels show the prominence of endothelial cells.

and found that all animals had a normal phenotypic appearance and normal fertility, litter size, lung morphology, and life span. Our highest-expressing line demonstrated a nearly 2 -fold (200\%) increase in 6-keto $\mathrm{PGF}_{1 \alpha}$ production after incubation of lung tissue homogenate with AA substrate. The fact that a line with a high copy number by Southern analysis and strong expression by Northern blot had only a 2 -fold increase in functional lung tissue PGIS activity may be explained by either direct substrate $\left(\mathrm{PGH}_{2}\right)$ availability or transgene product stability. Despite only a 2 -fold increase in PGIS activity, PGIS-expressing mice exposed to chronic hypoxia developed no evidence for pulmonary hypertension and had RVSP that was $60 \%$ lower than that of their nontransgenic littermates. The RVSP for transgenic animals did not change from baseline after 5 weeks of chronic hypoxia. Furthermore, the vessel wall thickness of small to medium-sized arteries was approximately one-third thinner in PGIS-expressing mice after chronic hypoxia and was indistinguishable from low-altitude control mice, demonstrating that no vascular remodeling occurred in transgenic animals. A gene-dosing effect may be present, although our lower-expressing line (line 7), with a $47 \%$ increase in 6 -keto $\mathrm{PGF}_{1 \alpha}$ production, was not protected from the development of pulmonary hypertension after exposure to chronic hypoxia. We speculate that the reason why the increase in 6-keto $\mathrm{PGF}_{1 \alpha}$ is not translated into a statistically significant reduction in pulmonary hypertension is a "threshold" effect. A threshold level of expression implies that a certain level of PGIS expression is necessary for the protective effect. Clearly, a $200 \%$ increase in 6-keto $\mathrm{PGF}_{1 \alpha}$ production affords protection. However, a $47 \%$ increase is less likely to protect from the development of pulmonary hypertension, and a power analysis of the data suggests that 40 animals per group would be required to demonstrate a difference between $\mathrm{Tg}^{+}$and $\mathrm{Tg}^{-}$animals from this line.

The mechanisms of action whereby PGIS overexpression provides protection against the development of pulmonary hypertension are likely multifactorial. That the hematocrits of both $\mathrm{Tg}^{+}$and $\mathrm{Tg}^{-}$animals did not differ after exposure to hypobaric hypoxia makes changes in blood viscosity unlikely to account for the differences seen in the 2 groups of animals. Clearly, the pulmonary vasodilatory effect of $\mathrm{PGI}_{2}$ may provide protection. Transgenic animals do not exhibit a vasoconstrictive response (as assessed by RVSP) in response to acute hypoxia, whereas the $\mathrm{Tg}$ - littermates displayed an 18\% increase in RVSP upon exposure to acute hypoxia. $\mathrm{PGI}_{2}$ has antiproliferative effects on vascular smooth muscle cells $(4,5)$, and transfection of the PGIS cDNA has been shown to decrease proliferation of vascular smooth muscle cells in culture (12). The results of these transfection studies (12) showed that overexpression of PGIS inhibited the growth of vascular smooth muscle cells in culture at a level of 6keto $\mathrm{PGF}_{1 \alpha}$ production found in our transgenic animals (a 2-fold increase in 6-keto $\mathrm{PGF}_{1 \alpha}$ production). Taken together, these findings are consistent with our data of significantly less vessel wall hypertrophy in the arteries of chronically hypoxic PGIS-expressing animals. PGIS overexpression may directly affect the level of prostacyclin production, as demonstrated by the increase in 6-keto PGF $1 \alpha$ production in the lungs of transgenic animals. However, another possibility for the observed effect is that other prostanoids are produced in smaller amounts owing to the siphoning of substrate toward the production of $\mathrm{PGI}_{2}$. For example, there might be a decrease of lung production of thromboxane, or, alternatively, higher $\mathrm{PGI}_{2}$ lung levels may oppose the action of thromboxane, leukotrienes, and platelet-activating factor. It is known that $\mathrm{PGI}_{2}$ can also upregulate lung cyclooxygenase-2 expression (31). Deter- 
mining whether the observed effects are due to excess prostacyclin itself, diminished production of other prostanoids, or other counterregulatory mechanisms was not the goal of the present study.

In summary, transgenic mice that express rat PGIS in the distal lung epithelium develop no pulmonary hypertension after exposure to hypobaric hypoxia. The demonstration that PGIS overexpression can prevent the development of pulmonary hypertension, together with the finding of decreased expression of PGIS in the lungs of patients with severe pulmonary hypertension (17), has important implications for the pathogenesis and treatment of severe pulmonary hypertension. We conclude that $\mathrm{PGI}_{2}$ can play a major role in regulating pulmonary vascular tone in response to acute and chronic hypoxia and can modify vascular remodeling in these conditions.

\section{Acknowledgments}

The 3.7 hSP-C promoter construct was a generous gift from Jeffrey A. Whitsett. We thank Jon Neumann for generating the transgenic animals. This work was supported by National Heart, Lung, and Blood Institute grants HL-03001 (to M.W. Geraci) and HL-43180-04A (to N.F. Voelkel and M.W. Geraci), by a Howard Hughes Foundation Individual Investigator Award (to M.W. Geraci), and by a grant from the PPH Cure Foundation (to N.F. Voelkel, R.M. Tuder, and M.W. Geraci).

1. Bunting, S., Gryglewski, R., Moncada, S., and Vane, J.R. 1976. Arterial walls generate from prostaglandin endoperoxidases a substance (prostaglandin X) which relaxes strips of mesenteric and coeliac arteries and inhibits platelet aggregation. Prostaglandins. 12:897-913.

2. Shaul, P.W., Kinanae, B., Farrar, M.A., Buja, M., and Magness, R.R. 1991. Prostacyclin production and mediation of adenylate cyclase activity in the pulmonary artery: alteration after prolonged hypoxia in the rat. $J$. Clin. Invest. 88:447-455.

3. Moncada, S., and Vane, J.R. 1979. Pharmacology and endogenous roles of prostaglandin endoperoxides, thromboxane $\mathrm{A}_{2}$, and prostacyclin. Pharmacol. Rev. 30:293-331.

4. Libby, P., Warner, S.J.C., and Friedman, G.B. 1988. Interleukin 1: a mitogen for human vascular smooth muscle cells that induces the release of growth-inhibitory prostanoids. J. Clin. Invest. 81:487-498.

5. Owen, N.E. 1985. Prostacyclin can inhibit DNA synthesis in vascular smooth muscle cells. In Prostaglandins, leukotrienes, and lipoxins. J.M. Bailey, editor. Plenum Press. New York, NY. 193-204.

6. Jugdutt, B.F., Hutchins, G.M., Bulkley, B.H., and Becker, L.C. 1979 Infarct size reduction by prostacyclin after coronary artery occlusion in conscious dogs. Clin. Res. 27:177A. (Abstr.)

7. Ribeiro, L.G.T., et al. 1981. Prostacyclin in experimental myocardial ischemia: effects on hemodynamics, regional myocardial blood flow, infarct size and mortality. Am. J. Cardiol. 47:835-840.

8. Pereira, B., Wu, K.K., and Wang, L.H. 1993. Bovine prostacyclin synthase: purification and isolation of partial cDNA. Biochem. Biophys. Res. Commun. 197:1041-1048.
9. Hara, S., et al. 1994. Isolation and molecular cloning of prostacyclin synthase from bovine endothelial cells. J. Biol. Chem. 269:19897-19903.

10. Pereira, B., Wu, K.K., and Wang, L.H. 1994. Molecular cloning and characterization of bovine prostacyclin synthase. Biochem. Biophys. Res. Commun. 203:59-66.

11. Miyata, A., et al. 1994. Molecular cloning and expression of human prostacyclin synthase. Biochem. Biophys. Res. Commun. 200:1728-1734.

12. Hara, S., et al. 1995 Overexpression of prostacyclin synthase inhibits growth of vascular smooth muscle cells. Biochem. Biophys. Res. Commun. 216:862-867.

13. Rubin, L.J. 1995. Pathology and pathophysiology of primary pulmonary hypertension. Am. J. Cardiol. 75:51A-54A.

14. Christman, B.W., et al. 1992. An imbalance between excretion of thromboxane and prostacyclin metabolites in pulmonary hypertension. $N$. Engl. J. Med. 327:70-75.

15. Badesch, D.B., et al. 1989. Decreased arterial wall prostaglandin production in neonatal calves with severe chronic pulmonary hypertension. Am. J. Respir. Cell Mol. Biol. 1:489-498.

16. Rabinovitch, M., et al. 1988. Angiotensin II prevents hypoxic pulmonary hypertension and vascular changes in rat. Am. J. Physiol. 254:H500-H508.

17. Tuder, R.M., et al. 1999. Prostacyclin synthase expression is decreased in lungs from patients with severe pulmonary hypertension. Am. J. Respir. Crit. Care Med. 159:1925-1932.

18. Barst, R.J., et al. 1994. Survival in primary pulmonary hypertension with long-term continuous intravenous prostacyclin. Ann. Intern. Med. 121:409-415.

19. Barst, R.J., et al. 1996. A comparison of continuous intravenous epoprostenol (prostacyclin) with conventional therapy for primary pulmonary hypertension. N. Engl. J. Med. 334:296-301.

20. Walmrath, D., et al. 1995. Effects of aerosolized prostacyclin in severe pneumonia: impact of fibrosis. Am. J. Respir. Crit. Care Med. 151:724-730.

21. Walmrath, D., et al. 1996. Direct comparison of inhaled nitric oxide and aerosolized prostacyclin in acute respiratory distress syndrome. Am.J. Respir. Crit. Care Med. 153:991-996.

22. Zobel, G., Dacar, D., Rodl, S., and Friehs, I. 1995. Inhaled nitric oxide versus inhaled prostacyclin and intravenous versus inhaled prostacyclin in acute respiratory failure with pulmonary hypertension in piglets. Pediatr. Res. 38:198-204.

23. Glasser, S.W., et al. 1988. Two SP-C genes encoding human pulmonary surfactant proteolipid. J. Biol. Chem. 263:10326-10331.

24. Korfhagen, T.R., et al. 1990. Cis-acting sequences from a human surfactant protein gene confer pulmonary-specific gene expression in transgenic mice. Proc. Natl. Acad. Sci. USA. 87:6122-6126.

25. Kaur, S., et al. 1989. Targeted ablation of alpha-crystallin-synthesizing cells produces lens-deficient eyes in transgenic mice. Development. 105:613-619.

26. Halbower, A.C., Mason, R.J., Abman, S.H., and Tuder, R.M. 1994. Agarose infiltration improves morphology of cryostat sections of lung. Lab. Invest. 71:149-153.

27. Voelkel, N.F., et al. 1996. Inhibition of 5-lipoxygenase-activating protein (FLAP) reduces pulmonary vascular reactivity and pulmonary hypertension in hypoxic rats. J. Clin. Invest. 97:2491-2498.

28. Westcott, J.Y., et al. 1986. Analysis of 6-keto PGF 1 $\alpha$, 5-HETE and LTC4 in rat lung: comparison of GC/MS, RIA, and EIA. Prostaglandins. 32:857-873.

29. Fagan, K.A., et al. 1999. The pulmonary circulation of mice with either homozygous or heterozygous disruption of endothelial nitric oxide synthase is hyperresponsive to chronic mild hypoxia. J. Clin. Invest. In press.

30. Ivy, D.D., et al. 1997. Prolonged endothelin A receptor blockade attenuates chronic pulmonary hypertension in the ovine fetus. J. Clin. Invest. 99:1179-1186.

31. Chida, M., and Voelkel, N.F. 1996. Effects of acute and chronic hypoxia on rat lung cyclooxygenase. Am. J. Physiol. 270:L872-L878. 